\title{
Learning Analytics: Online Higher Education in Management
}

\author{
Eulalia Torras Virgili
}

OBServatory, OBS Business School, Spain

Copyright $\bigcirc 2019$ by authors, all rights reserved. Authors agree that this article remains permanently open access under the terms of the Creative Commons Attribution License 4.0 International License

\begin{abstract}
Learning analytics are a set of methods and techniques that collect, process, inform and successfully produce machine-readable data continuously to analyze the educational process and enable improvement decisions. The research aim is to develop and verify an instrument, based on theoretical contributions accepted by the international community that can evaluate the quality of online higher education in management based on Learning Analytics methods. The online teaching-learning model in management proposed that students' actions focused on an educational activity should be in the central position. This online teaching-learning model in management has been proposed according to five components: institution management, technological presence, instructional design, intra-psychological component and an inter-psychological or social component. Building upon the Teaching and Learning in Online Education Institutions in Management Model, an instrument has been created and provided that includes the dimensions, categories and variables of each component. Analyzing these components, we see that the dimensions, categories and variables for each are adequate to support the analysis of online higher education institutions in management.
\end{abstract}

Keywords Learning Analytics, Online Higher Education, Model, Management, Psychology

\section{Introduction}

Learning analytics are a set of methods and techniques that collect, process, inform and successfully produce machine-readable data continuously to support educational environment and provide insights into learning processes [1].

In general, these procedures initially emphasize the measurement and collection of data and preparation for processing during learning activities. These procedures focus on the analysis, the presentation of data and the interpretation of results. This, in turn, informs and empowers students, instructors, and organizations regarding their performance thereby and achievement of objectives thereby, facilitating decision making accordingly [2].

Learning analytics and educational data mining share similar objectives and focus on the intersection of learning science and data-based analytics but show. Nonetheless, there are differences in their origins, their techniques, in what fields they emphasize and in types of discovery.

The main objective of learning analytics is to extract information from educational data to support educationrelated decision making. This information can be targeted to different stakeholders [3]. Thus, teachers can receive feedback to evaluate the structure of their courses and the proper development of the learning process. These data can help to quickly identify students who are having trouble difficulty following the course, as well as the topics that generate the most confusion.

Students can receive recommendations on resources according to their performance, goals and motivations, can graphically analyze the results of their learning process, compare them with those of the rest of the class, and observe the performance and contributions related to collaborative activities. Managers can use information to design a better allocation of human and material resources to improve the overall quality of their academic experience [4].

In general, the fundamental difference between learning analytics and educational data mining is that the latter focuses more on techniques and methodologies, while learning analytics deals more with applications. However, these differences seem to be less and less noticeable as both fields evolve over time. It seems very likely that in the future that the limits between learning analytics and data mining in education will disappear.

Getting to know student's preferences is a complex task. Simply asking students what they want is too invasive and error-prone. On the other hand, monitoring behavior discretely and discovering meaningful patterns is difficult and computationally slow.

In any case, capturing the user's exact preferences is an 
essential task because the systems of tomorrow must respond dynamically to the changing needs of their students [5].

Recommendation systems learn the preferences of their students over time through both discrete monitoring and relevant feedback. The construction of accurate user profiles is a difficult process. In general, a recommendation system must work with variables that generate noise while also producing meaningful information in regard to the interest of the student, using web browsing records or product purchase records. To be successful, must be select a profile representation that match this domain, and an adequate set of profile techniques employed.

These recommendations are developed by finding similar users and recommending the materials they may like, which is known as collaborative filtering or content-based filtering. Ontology is a conceptualization of a domain in a comprehensible environment with a machine-readable format consisting of entities, attributes, relationships and axioms. Ontology can provide a rich conceptualization of the work domain of an organization, representing the main concepts and relationships of work occupations [6]. These relationships could involve isolated items of information, such as an employee's home phone, or include and activity such as authoring a document, or attending a conference.

Ontology is commonly used in knowledge-based systems to define the classes and structure of supported domain models. Ontology is used in such a way that we can move forward using inference, assignment to external knowledge bases and mapping for human-comprehensible concepts.

There are a variety of techniques with this objective. Some of them are taken from classical statistics, such as the Pearson's-r Correlation. Other techniques include Probabilistic Methods based on the Bayes' Theorem, Principal Component Analysis, and others. Some are more recent such as learning analytics and educational data mining [7].

As we have pointed out above, one of the biggest challenges that teachers face today is evaluating the students' learning as they develop learning activities in the virtual environment. This is why teachers usually choose information and communication technologies that allow them to have evidence of work done enabling them to reach a fair evaluation, especially when these activities require collaborative work.

The interaction of students in the virtual environment using online applications (social networks, forums, virtual teaching and learning environments, etc.), provides data that is recorded on the servers, in so-called system logs. More and more LMS platforms and other technological environments make it easier to obtain statistics on student performance and the degree of interaction with colleagues, for example the number of connections or the number of messages sent. Even so, part of this data is not stored in the system logs and is lost.

Thanks to the indicators and the metrics analyzed we can have information about the performance of a student throughout an activity and help, preventively, to achieve the learning objectives if any of the indicators reveal a significant deviation [8]. Online teaching and learning environments, Moodle, Canvas, Blackboard, etc. include additional learning analytics tools that provide very useful information about students' activity on the platform. Some of these LMS platforms provide real time data that the teacher can consult to answer different questions regarding the teaching-learning process. For example, if a student expresses a doubt about a concept, the teacher can access the indicators and metrics to verify if the student has reviewed the material in which the concept is examined. Should that not be the case, the teacher's response will be to indicate to the student suggest that the student reads the material that covers the key point.

The implementation of indicators and metrics in LMS platforms solves the key issue of automating information and being able to immediately access it. That means that access to data is not only more complete than without learning analytics, it is also simpler and faster [9].

The teaching-learning process is developed beyond the LMS platforms. For example, cooperative work among students can be enriched if the interaction is mediated by open resources. The activity of the students in these open resources is not stored on system logs, and is therefore lost. Learning does not occur only in closed and formal environments, but by definition reaches beyond these virtual environments. It is neither appropriate nor possible to limit activity to a single technological platform.

Learning analytics offer a more personalized learning process, enabling a more effective learning experience [10]. This personalized learning experience is enabled by the common ability to monitor each student's pace using the data that is automatically collected by most LMS platforms. Therefore, the interaction of the students during the course leads them to be active agents in the development of their own curriculum.

In view of the above, we consider the use of Learning Analytics to analyze the actions of online higher education institutions in management an interesting option. This requires a theoretical model built on the main contributions to the field of online higher education. This theoretical model will enable the identification of the components, dimensions, categories and variables to be used in Learning Analytics.

The research aim is to develop and produce a model based on theoretical contributions accepted by the international community and an instrument to evaluate the quality of online higher education in management based on the Learning Analytics methods.

\section{Materials and Methods}


Our proposal was to develop an instrument for analyzing online learning environment quality. To obtain evidence of this, we opted for a Learning Analytics methodology based on a theoretical model. This methodological option was chosen because our research aim involved the process of teaching and learning. Experimental manipulation and strict control were not involved because learning must be considered in its context and direct data from participant interaction is essential.

This instrument has been tested at OBS Business School. OBS Business School is an international online higher education institution in management based in Spain that offers an online Master's Degree. Visualization is the learning analytics method chosen for this first approach. The methodology is specified in three phases:

1. Development of the Theoretical Model on Teaching and Learning in Online Education Institutions in Management. This theoretical model is based on the main international references.

2. Production of an instrument based on the components, dimensions, categories and variables of the Theoretical Model on Teaching and Learning in Online Education Institutions in Management.

3. Exploratory phase to collect evidence of the adequacy of the instrument. The collection will focus on one of the components.

\subsection{Units of Analysis}

It is essential to apply learning analytics based on an online higher education educational model in management. The reason for this is that the key in the use of Learning Analytics lies in the interpretation of the data obtained. Only if the data provides elements that can be analyzed together, can learning analytics serve as the basis for appropriate decisions.

In this sense, the online teaching-learning model in management places student's actions focused on an educational activity in the central position. Therefore, the cognitive, social and affective dimensions will be fundamental. Interaction is required to make sense of these actions. Interaction with the physical environment, with technologies and materials, and interaction with the social environment, teachers and peers, will allow us to grasp the teaching-learning process.

\subsection{Model for Learning Analytics}

The unit of analysis was divided into five components linked to the online teaching and learning process theoretical framework (see figure 1):

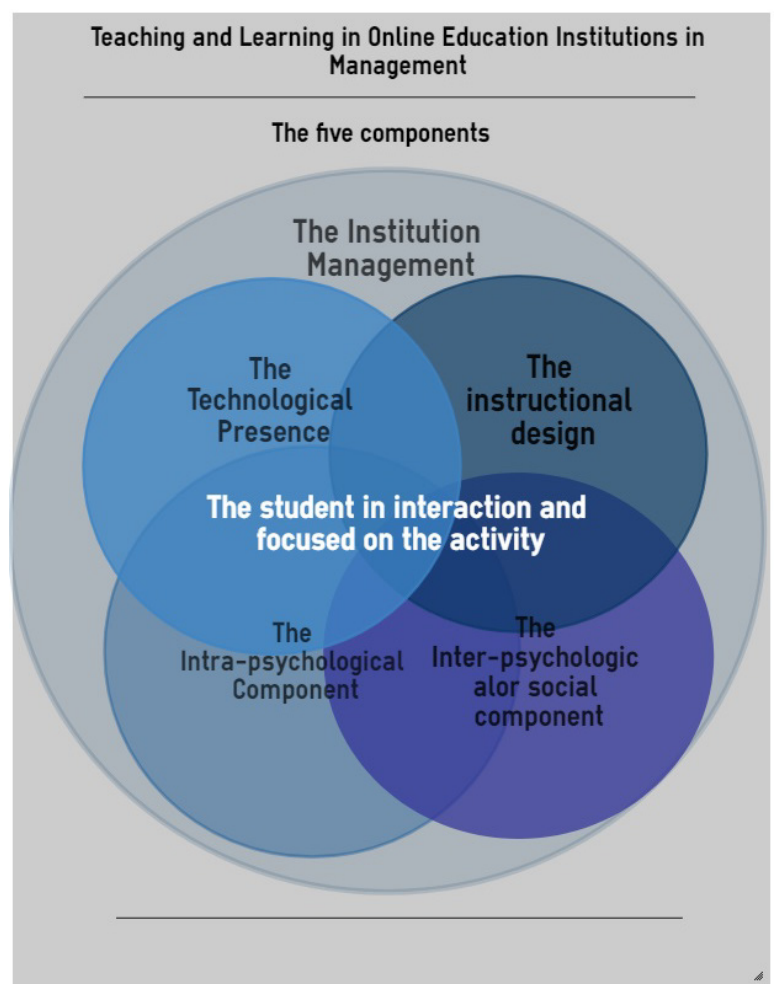

Figure 1. Teaching and Learning in Online Education Institutions in Management.

Component 1. Institution management - Management is based on standards (standardizations, schedules and subject and evaluation standards), in the community (the different groups that perform these functions) and on the division of labor (including coordination) Yrjö Engeström at University of Helsinki has developed since the 90s the model of learning by expansion, a theoretical approach centered on activity. This approach is based on the theory of activity, expansive learning and the development of human resources. This approach is suitable for the Learning Analytics because it links the educational process that takes place in the institution with the management of it. Management is based on standards (standardizations, schedules and standards of subjects and evaluation standards), in the community (the different groups that perform the functions) and in the division of labor (with the elements of coordination included) (see figure 26).

Even so, in technological and changing environments such as current organizations, the challenge lies in the perspective ratio of dependence on cognitive paths and the stabilization of these cognitive paths.

Cognitive paths open up the possibility of analyzing the horizontal dimension of the expansion of learning in terms of improvable daily actions, something that is urgently needed when we want to make sense of fragmentary, often unremarkable elements. For example, when a management standard is applied in the teaching-learning process without knowing or reflecting on the underlying criterion, it is very likely that this standard will lose its 
value when the scenario contemplates modifications.

If the perspective dependency ratio of cognitive paths is not taken into account, far from adapting the standard to changes, it often remains a stumbling block for good management. The perspective dependency ratio of cognitive pathways and their stabilization are analytical resources that make the theory of cognitive paths empirically useful beyond their theoretical formulation. Although difficult to perceive the cognitive paths are real and everyday, affecting the whole institution. It is necessary to maintain the know-how in order to analyze if these cognitive paths are adequate in the present scenario of the institution (see figure 27) (see figure 2) [11, 12].

Component 2. Technological presence- Technological presence is defined as a wide range of behaviors that constitute the online interaction styles of the students. A selection of the behavioral records registered in the online learning environment will define technological presence. The investigations of online teaching-learning processes tend to give a more restrictive meaning to the technological presence. This meaning is oriented to the access possibilities of students and teachers, to technology and its influence on learning, rather than to students' own interaction with technology.

Therefore, in these investigations the technological presence is measured based on indicators based on learning objects understood as "digital material - for example graphics, text, audio, animation or interactive tools specially designed to involve and motivate students" ( Baker \& Siemens, 2014) or indicators that measure the influence of technology on students' results by comparing face-to-face teaching-learning processes with online processes.

Consequently, with the broad meaning of technological presence that we propose, we consider it necessary to define the technological presence based on metrics that measure, not only the fact that the teaching-learning process includes technology but also, and especially, indicators that Emphasize the behaviors that participants have in the online learning environment. Therefore, we consider it relevant to analyze the student's technological presence profile, understanding it as a set of interaction behaviors with the online teaching environment. This profile of technological presence is related to the type of environment.

The relevance of each behavior is associated with the precise environment; therefore, the specific profile of technological presence is associated with particular situations. In other words, these behaviors are part of a technological presence profile based on the defined use of the online learning environment. [13, 14].

Component 3. Instructional design- Three primary levels of interactions illustrate the relationship between learning theories, instructional strategies and student interactions with human and non-human resources that include the use of emerging technologies to facilitate electronic learning. These three primary levels are the cognitive dimension, social interaction and human and non-human interaction the instructional design is often presented as a concept reduced to a procedure to follow to design online training, however, there are several models that collect this procedure.

Among them, the ADDIE model is one of the best known (ADDIE model reflects an interactive instructional design process.) ADDIE is the acronym of the model, according to its phases (analysis, design, development, implementation and evaluation).

The final product of a phase is the product of the beginning of the next phase. In any case, it is possible to return to previous phases at any time. The phases of the model are the following:

- Analysis. The initial step is to analyze the students, the content and the environment whose result will be the description of a situation and their training needs.

- Design. A program of the course is developed with particular attention to the pedagogical approach and the way of sequencing and organizing the content.

- Developing. The real creation (production) of the contents and learning materials based on the design phase.

- Implementation Execution and implementation of the training action with the participation of the students.

- Evaluation. This phase consists in carrying out the formative evaluation of each of the stages of the ADDIE process and the summative evaluation through specific tests to analyze the results of the training action. $[15,16]$.

Component 4. Intrapsychological component- The analysis of the psyche, and therefore, the analysis of a person's internal experience during the learning process, can start by distinguishing the cognitive dimension (perception, language, thought, reflection, etc.), the affective dimension (the emotions, feelings, affections, etc.) and the motivational dimension (goals, expectations, achievements, etc.) Learning allows people to adapt to the social and physical reality that surrounds them. The person who learns does so with interaction with other people and in a physical context so that this relationship is part of the learning process itself. This construction of mental representations, the intrapsychological or cognitive dimension that involves learning is done with interaction with the context. For example, if a student asks the teacher then you cannot separate the student's doubts from the teacher's answers. Knowledge emerges in the interaction between the student and the teacher.

It is fundamental to consider that the interactions in online education must be planned: they cannot be left to spontaneity. A good planning of online interactions involves five criteria: 
- Continuity- The interaction between teacher and students, between students among themselves and between participants with the environment must be maintained over time.

- Natural exhaustion of the subjects- The interaction must maintain the fundamental characteristic of communication that implies that the discourse around the topics can be maintained naturally until the closing date.

- Limited anticipated vision- The intervention of the teacher must be flexible in terms of facilitating adaptation to these unpredictable elements. It is essential to keep the student focused on the activity in the center of attention of the process.

- Communications without errors- The messages must be precise and clear, avoiding errors.

- Information sources and expandable resources- As the training process goes by, the design should facilitate the incorporation of new elements not related to planning but to the possibility of accessing information sources. [17, 18].

Component 5. Interpsychological or social componentInterpsychological or social presence is the ability of learners to project their identities within the learning community of inquiry emphasizing the traits that enable progress in learning The analysis of the psyche, and therefore, the analysis of the interior of the person when he learns, can start from the distinction of the cognitive dimension (perception, language, thought, reflection, etc.), the motivational dimension (the goals, expectations, achievements, etc.), the affective dimension (emotions, feelings, affections, etc.) and the ethical dimension.

Socioconstructivism displaces learning as an exclusive product of consciousness placing it in language. That is, language is the mediating tool of learning, the speech habits used by students are regulators of mental representations.

The mediation of language therefore promotes reflection on impulsivity due to two of its main characteristics: time and the semantic factor. Regarding time, verbal mediation provides distance between the stimulus and the response. The time used in reflection affects the people who interact. For example, by dynamizing the resolution of a conflict of professional practice, the teacher can comment on the student who is trying to address the issue based on a concept explained in the subject. These words stop the initial impulsiveness of responding from the routine so that the construction of the mental representation is also mediated by this delay in the response.

Verbal mediation includes meaning filtering and semantic attention, as representations that may include self-talk. For example, before a student who has an unsafe attitude with the application of a procedure, the teacher can reflect on the cause and strengthen their ability to understand the application. In this case, the role of verbal mediation is marked by the meaning of the phrase itself. If the teacher is aware that the student's insecurity may have a cause then she will act prudently helping to build a mental representation of the tablet as a learning tool.

Transformation is possible because of the unique experiences that lead people to maintain episodes of verbal interaction with others. These experiences have different moments:

1. The first phase is called basic knowledge. This first phase takes place when the online teacher expresses his experiences by verbalizing tacit or explicit knowledge and when the student reads the materials.

2. Phase two is the call for personal use. This second phase begins when students begin to use the concepts shared by the teacher and the materials. The emotions that are used on a personal level are established in a more natural way in a later use of mental representations.

3. In phase three there is a use of knowledge itself. In phase three, the sequence moves toward a use of mental representations during interactive instructions and online teacher guidance. In this phase, language also has a prominent role.

4. Phase four is modeling and teacher feedback to students. This phase occurs when the transfer of knowledge has already passed through the interpsychological plane and the intrapsychological plane.

5. In phase five, the practice with the students takes place. This phase has its origin in the interpsychological planes.

6. Finally, phase six is characterized by the signals between the online teacher and the students. In this case, the signals between teacher and students have an impact on the reflection that the teacher makes before modeling the knowledge.

The ethical dimension is key in Learning Analytics. The theory of basic human values, developed by Shalom H. Schwartz (2005), is a reference in the field of intercultural research (Schwartz, 2005). This model measures the universal values that are recognized in all major cultures. Schwartz's theory identifies ten motivationally distinct values and describes the dynamic relationships between them. To better represent these relationships graphically, the theory organizes the ten values in a circular structure. [19,20].

Each component is associated with dimensions, categories and variables that support a general level of maturity of each component. These dimensions, categories and variables allow us to analyze and describe the events in the classroom and the institution. Therefore, these dimensions, categories and variables allow us to operationalize theoretical constructs and specify them as appropriate factors and statistics. Figure 1 shows an example: dimensions, categories and variables for the component 1 that we refer to as "institution management". 


\section{The institution management}

\section{Rules}

Economic resources (compares with

similar institutions]

The availability of private capital The availability of own capital The low cost of capital Total sales

\section{Community}

\section{Group Development}

The right working conditions: payments

The costs of realistic human resources

Remuneration indices according to performance

Salary policy index as a human resources

development program

Success rate for the implementation of the salary

policy program as teacher development

Identification of the training needs of employees

Percentage of achievement of the objectives of

employee training

Percentage of implementation of the employee

training plan

Evaluation ratings of employee training

Performance appraisal rates

Group motivation rates

Success rate of the motivation plan

Change management

Management of the conflict

Management of the groups

Identification of potentials

HR development program

Rotation index

Success rate of the career plan

Collaboration indexes

Recognition indices

Transformational leadership

Collegiality

Shared vision

Appreciation of learning

Crystallization of knowledge

\section{Division and coordination of work}

\section{Task}

The planning

The control

The differentiation

The coordination

The linking devices.

The decision making

\section{Law}

The educational legislation

Civil and commercial legislation

Criminal legislation

The contractual legislation

\section{Individual Development}

The knowledge: online education The skills: online education

Values and beliefs

Confluence to the common good

The level of satisfaction of students in

relation to personal

Percentage of student dropouts per

teacher.

Ratio student/teacher

Ratio student/manager

\section{Technologies adjustment}

Innovation

Transference

Technological diffusion

Accessibility

The management of technological change.

Figure 2. Dimensions, categories and variables for component 1 institution management

\subsection{Instrument}

Based on Teaching and Learning in Online Education Institutions in Management, an instrument has been created that collects the dimensions, categories and variables of each component. This instrument should be used as a basis for analysis using Learning Analytics. At the same time, this instrument enables us to obtain data regarding the quality of the institution for an analysis prior to the use of Learning Analytics. Table 1 shows the number of dimensions, categories and variables for each component.

The structure of the scale is based on the methodology used by [12], for the evaluation of higher education 
institutions. Said methodology proposes the following five levels of analysis: not, a few, some, enough, many. This instrument is public: https://es.surveymonkey.com/r/7DPWGD2

Table 1. The Number of Dimensions, Categories and Variables For Each Component.

\begin{tabular}{|c|c|c|c|}
\hline Component & Dimension & Category & Variable \\
\hline The institution management & 3 & 6 & 60 \\
\hline The technological presence & 2 & 5 & 57 \\
\hline The instructional design & 3 & 6 & 35 \\
\hline The intrapsychological component & 3 & 6 & 42 \\
\hline $\begin{array}{c}\text { The interpsychological or social } \\
\text { component }\end{array}$ & 3 & 29 & 237 \\
\hline Total & 14 & & \\
\hline
\end{tabular}

\section{Results}

The results have been obtained using Atlas/ti. The results of the Master's Degree classroom analysis show that the interpsychological or social component can be adequately analyzed based on the dimensions, categories and variables proposed by the Model Teaching and Learning in Online Education Institutions in Management. The identified variables are shown in figure 3 .

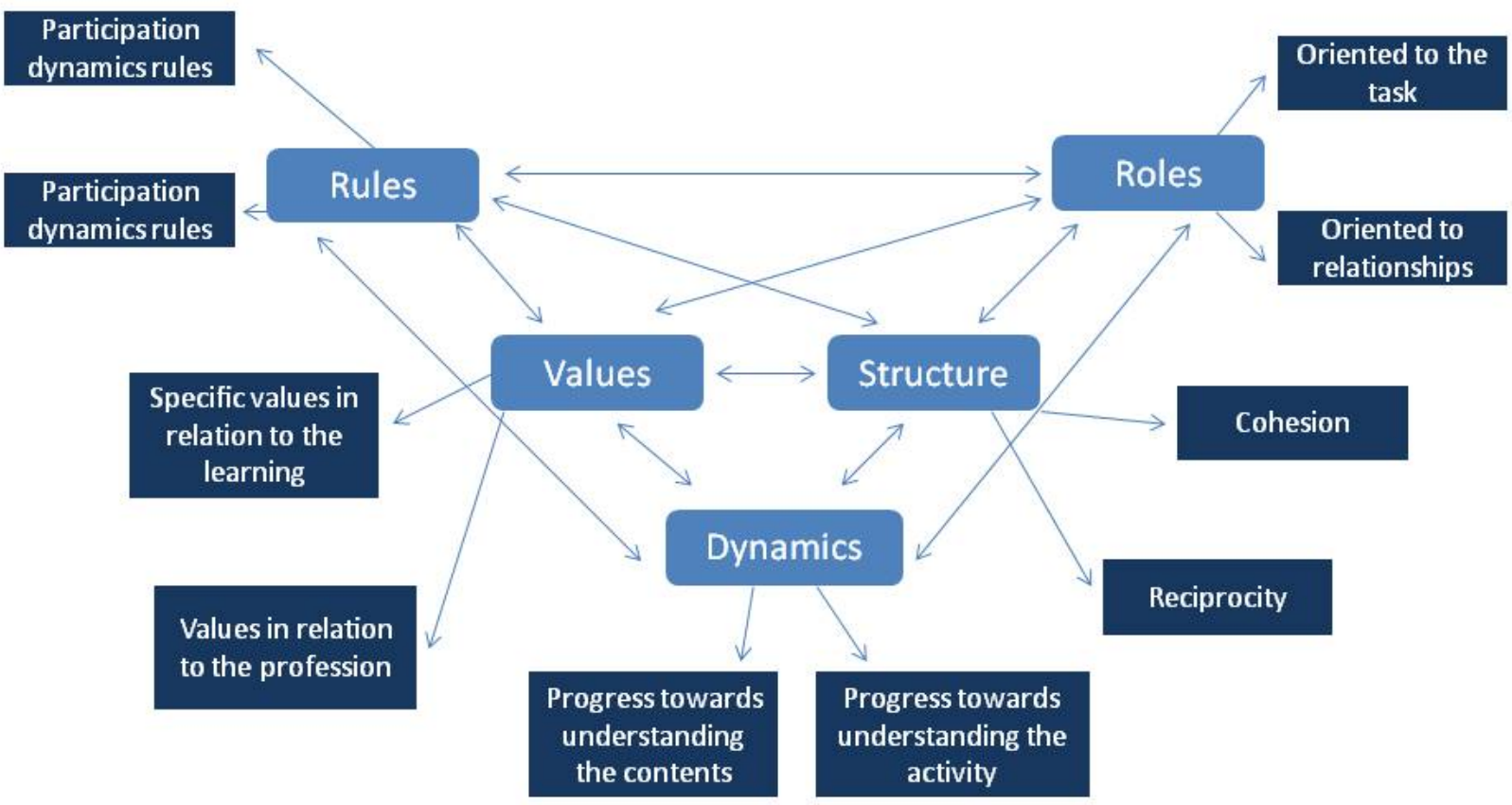

Figure 3. Dimensions, Categories and Variables for the Component 1 the Institutions Management.

According to the Online Higher Education in Management the others metrics identify are: (table 2): 
Table 2. Online Higher Education in Management Metrics.

\begin{tabular}{|c|c|c|}
\hline Dimensions & Categories & Key Performance Indicators \\
\hline \multirow{10}{*}{$\begin{array}{l}\text { Roles focused on the } \\
\text { teaching-learning process }\end{array}$} & \multirow{4}{*}{ Oriented to the task } & Planner \\
\hline & & Informer \\
\hline & & Reflexive \\
\hline & & Anecdotal \\
\hline & \multirow{6}{*}{ Oriented to relationships } & Management of anxiety \\
\hline & & Time management \\
\hline & & Management of fears \\
\hline & & Positivity \\
\hline & & Acceptance \\
\hline & & Commitment \\
\hline \multirow{6}{*}{ Rules } & \multirow{4}{*}{ Rules of participation dynamics } & $\begin{array}{l}\text { Explanation of the rules for participation in the } \\
\text { debate }\end{array}$ \\
\hline & & $\begin{array}{l}\text { Explanation of the rules for participation in the } \\
\text { blog }\end{array}$ \\
\hline & & $\begin{array}{l}\text { Explanation of the rules for participation in the } \\
\text { wiki }\end{array}$ \\
\hline & & $\begin{array}{l}\text { Explanation of the delivery for the training } \\
\text { activities }\end{array}$ \\
\hline & \multirow{2}{*}{ Rules in the preparation of activities } & Explanation of standards in relation to content \\
\hline & & Explanation of standards in relation to form \\
\hline \multirow{9}{*}{ Values of the learning community } & \multirow{3}{*}{$\begin{array}{l}\text { Specific values in relation to the } \\
\text { teaching-learning process }\end{array}$} & $\begin{array}{l}\text { Positive evaluation of the teaching-learning } \\
\text { process }\end{array}$ \\
\hline & & Orientation to the learning process \\
\hline & & Commitment to deepen the content \\
\hline & & Commitment to expand the content \\
\hline & & Commitment to apply the content \\
\hline & \multirow{4}{*}{ Values in relation to the profession } & Identity as a teacher / student \\
\hline & & Commitment to the profession \\
\hline & & Identity as professional / future professional \\
\hline & & $\begin{array}{l}\text { Positive assessment of the professional } \\
\text { community / profession }\end{array}$ \\
\hline \multirow{4}{*}{ Structure } & Cohesion & Cohesion expression \\
\hline & & Cohesive network \\
\hline & Reciprocity & Response to the contributions of a partner \\
\hline & & $\begin{array}{c}\text { Tribute given to the contributions of a } \\
\text { companion }\end{array}$ \\
\hline \multirow{6}{*}{ Dynamic } & \multirow{2}{*}{ Progress towards understanding the contents } & Verbalizations of understanding of concepts \\
\hline & & Expression of doubts \\
\hline & & $\begin{array}{l}\text { Answers to the doubts of colleagues in relation } \\
\text { to concepts }\end{array}$ \\
\hline & \multirow{2}{*}{ Progress towards understanding the activity } & $\begin{array}{l}\text { Verbalizations of the understanding of the } \\
\text { activity }\end{array}$ \\
\hline & & Expression of doubt in relation to the activity \\
\hline & & $\begin{array}{l}\text { Answers to the doubt of colleagues in relation to } \\
\text { the activity }\end{array}$ \\
\hline
\end{tabular}

\section{Discussion}

Learning Analytics presents the risk of starting from very high expectations. As any technological trend, it has appeared linked to the hope of generating a profound change at online higher education institutions. For the proper Learning Analytics it is necessary to overcome unrealistic expectations and apply the method to respond to the challenges that management, the teaching-learning process and technology pose in online higher education 
institutions in management.

The need to respond to the daily challenges of higher education institutions in online management using the Learning Analytics method raises the necessary reflection on how to face these challenges: the key seems to be the creation of an interdisciplinary team formed by an expert in educational psychology, a computer scientist and an expert in the management of the institution.

Research questions should be the axis for the use of Learning Analytics. Like any other research method, Learning Analytics requires a sustained use by the formulation of specific and contextualized questions that provide answers to the day-to-day demands of institutions.

Metrics are the key to the proper use of Learning Analytics; identifying the appropriate metrics to answer research questions will allow higher education institutions in online management to advance with the use of this method. Learning Analytics, as a method that manages large amounts of data, presents as the main technical difficulty the preparation of the data involving a time that is necessary to consider.

It is increasingly economical to store data so that the tendency to store information and wait for results to offer evidence is a temptation. Storing and preserving the data involves the risk of getting lost among the information.

Therefore, a balance is necessary between the storage of data for its possible use and the elimination of these. Learning Analytics techniques are classified as supervised learning and supervised learning. Regression, classification and decision trees are, in this order, the most used techniques of supervised learning. Clustering, K-means clustering and the Neural Network are the most used unsupervised learning techniques.

\section{Conclusions}

The components analyzed show that the dimensions, categories and variables for each are adequate to support the analysis of higher education institutions in management. We consider that the identification of the statistics is valid to sustain an evaluation process whether this process is based on the Learning Analytics or based on the use of the instrument in its version of the questionnaire. In future research, it is planned to use the Teaching and Learning in Online Education Institutions in Management model to evaluate European and South American institutions.

The components analyzed show that the dimensions, categories and variables for each one are adequate to support the analysis of higher education institutions in management. We consider that the identification of these statistics can sustain a valid evaluation process whether this process is based on Learning Analytics or based on the use of this instrument in the version in our questionnaire. In future research, we are planning to use the Teaching and Learning in Online Education Institutions in Management model to evaluate European and South American institutions.

Currently the theoretical models that support Learning Analytics are mostly technological; therefore, they are models focused on giving answers to the handling of the data. Despite the youth of this field and its constant growth, development and change, it is possible to identify five technological models that are referents in the Learning Analytics literature (Chatti, 2012[22]; Picciano, 2012, [23] Gartner, 2012; [24] Clow, 2012; [25] Siemens, 2013) [26].

Given that technological models respond to data management, it is essential to be guided by management and behavior models to identify which data should be analyzed.

The balanced scorecard is an excellent reference framework for developing Learning Analytics metrics. These metrics can be translated into results thanks to the large number of digital resources that are currently available. Starting from suitable metrics is necessary; to find these metrics, the theoretical models are essential.

The reason for this is that the key in the use of Learning Analytics lies in identifying the appropriate metrics to answer the questions that concern the institutions. The metrics should be understood as a set of variables whose joint interpretation allows the analysis of reality. Only if the data provide elements that can be analyzed together, then Learning Analytics can be the basis of appropriate decisions.

In this sense, developing a model for online teaching-learning institutions in management based on metrics is fundamental. This research has developed a model based on the balanced scorecard to make use of Learning Analytics in online teaching-learning institutions in management. This model places in the central position the actions of the student focused on an educational activity. Therefore, the cognitive, social and affective dimensions are fundamental. These actions make sense with the interaction. The interaction with the physical environment, the technologies and the materials, and the interaction with the social environment, the teacher and the peers, allow us to convey the teaching-learning process.

The online teaching-learning model in management is based on five perspectives that correspond to: instructional design, technological presence, intrapsychological/cognitive dimension,interpsychological / social dimension, institution management.

Each perspective is associated with dimensions, categories and variables that allow establishing a general level of maturity of each perspective. These dimensions, categories and variables allow analyzing and describing the day-to-day events of institutions and classrooms. At the same time these metrics allow their connection with 
daily questions that arise in institutions. Therefore, these dimensions, categories and variables allow to operationalize theoretical constructs and specify them in appropriate factors and statistics for decision making.

\section{Acknowledgements}

We are very grateful to OBS Business School.

\section{REFERENCES}

[1] R. Baker, Educational Data Mining: An Advance for Intelligent Systems in Education. IEEE Intelligent Systems, 1541-1672, 78-82, 2014.

[2] J. Heath, E. Leinonen, An Institution Wide Approach Learning Analytics. In Anderson, M. Developing Effective Educational Experiences through Learning Analytics, Hershey, IGI Global, 2016.

[3] H.I. Alabi, A Lenguaje and Space: Visualizing Learning Online. In Anderson, M. Developing Effective Educational Experiences through Learning Analytics, Hershey, IGI Global, 2016.

[4] Z. Papamitsiou, A. Economides, Learning Analytics and Educational Data Mining in Practice: A Systematic Literature. Review of Empirical Evidence. Educational Technology \& Society, 17/4, 49-64, 2014.

[5] S. L. Newman, B. Neimeyer, T. Seddon, A. Devos, Understanding educational work: exploring the analytic borderlands around the labour that enables learning, Globalisation, Societies and Education, 12/3, 65-73, 2014. https://doi.org/10.1080/14767724.2014.916609

[6] J. Watson, B. Kelly, R. Callingham,, J. M. Shaughnessy, The measurement of school students' understanding of statistical variation. International Journal of Mathematical Education in Science and Technology, 34, 1-29. 10.1080/0020739021 000018791. 2003.

[7] N. Noss, L. Hoyles, Learning, By Constructing and Sharing Models. Mathematical Modelling, Education, Engineering and Economics-ICTMA 12, 79-88, 2007 https://doi.org/10.1533/9780857099419.2.79

[8] A. Pardo, G. Siemens, Ethical and privacy principles for learning analytics. British Journal of Educational Technology, 45/3, 438-450, 2014.http://dx.doi.org/10.1111/ bjet. 12152

[9] J. Minguillón, C. Appel \& F. Santanach, Learning analytics in practice: setting up a laboratory for action research at the Universitat Oberta de Catalunya. In: Eighth EDEN Research Workshop, Oxford, 26th October, 2014.

[10] B. Dietz-Uhler, J. E. Hurn, Using Learning Analytics to
Predict (and Improve) Student Success: A Faculty Perspective. Journal of Interactive Online Learning, 12/1, 713-726, 2013.

[11] Y. Engeström, Developmental Work Research: Expanding Activity Theory in Practice. Berlin: Lehmanns Media, 2005.

[12] J. J. Alcolea et al, White book of institutional intelligence at universities, Madrid, OCU, 2013.

[13] E. Gregori, E. Torras, T.Guasch, Cognitive attainment in online learning environments: matching cognitive and technological presence. Interactive Learning Environments, 8, 1-17, 2011. https://doi.org/10.1080/10494820.2010.5310 26

[14] [14] L. Rourke, H. Kanuka, Barriers to critical discourse. International Journal of Computer Supported Collaborative Learning, 2/1, 105-126, 2007.

[15] N. Sclater, A. Peasgood, J. Mullan, Learning Analytics in Higher Education, Bristol, JISC, 2016.

[16] A. Hirumi, A framework for analyzing, designing, and sequencing planned elearning interactions, Quarterly Review of Distance Education 3/2, 141-60, 2002.

[17] [17] S.L. Jack, L.A. Anderson, Entrepreneurship education within the enterprise culture: Producing reflective practitioners. International Journal of Entrepreneurial Behavior \& Research, 5/3, 110-125, 1999. https://doi.org/1 $0.1108 / 13552559910284074$

[18] L.S. Vygotski, Thinking and Speech. New York, Plenun Press, 1997.

[19] B. Bloom, Taxonomy of educational objectives: Handbook I, The cognitive domain, Nueva York, David McKay \& Co., 1956.

[20] [20] R. Bodily, K. Verbert, Proceedings of the Seventh International Learning Analytics \& Knowledge Conference, 309-318, Vancouver, British Columbia, Canada, March 13th, 2017.

[21] S. Ryza, U. Larenson, S. Owen, J. Wills, Advanced Analytics with Spark, O'Reilly, Boston, 2017.

[22] Chatti, M.A., Dyckhoff, A.L., Schroeder, U. \& Thüs, H. (2012) A Reference Model for Learning Analytics. International Journal of Technology Enhanced Learning (IJTEL) - Special Issue on "State-of-the-Art in TEL".

[23] Picciano, AG (2012). The Evolution of Big Data and Learning Analytics in American Higher Education. Journal of Asynchronous Learning Networks, 16 (3), 9-20.

[24] Gartner, G (2016). Learning Analytics: expectations and predictions. Community \& Society. Recuperado de: http://www.greller.eu/wordpress/?p=4505

[25] Siemens, G (2004). Connectivism: A Learning Theory for the Digital Age. International Journal of Instructional Technology and Distance Learning, 2, 3-10. 